\title{
Effect of Substrate Grain Size on the Growth, Texture and Internal Stresses of Iron Oxide Scales Forming at $450{ }^{\circ} \mathrm{C}$
}

\author{
C. Juricic $\cdot$ H. Pinto $\cdot$ D. Cardinali $\cdot$ M. Klaus • \\ Ch. Genzel · A. R. Pyzalla
}

Received: 12 November 2008/Revised: 8 June 2009/Published online: 21 July 2009

(C) The Author(s) 2009. This article is published with open access at Springerlink.com

\begin{abstract}
The oxidation behavior of iron polycrystals and single crystals with (110) surface orientation was studied at $450{ }^{\circ} \mathrm{C}$. Energy-dispersive diffraction with synchrotron radiation provided in situ information regarding the evolution of stress gradients and fiber texture in the oxide scales. Within this low-temperature regime, grain boundaries caused the oxidation kinetics of polycrystalline iron to be more rapid than iron single crystals only during the first minutes of oxidation. Epitaxial growth of iron oxides occurred only on single crystal substrates during the initial oxidation. In situ stress analyses suggested that stress relief occurred invariably in the magnetite layer due to the formation of a fine-grained seam near the iron substrates. Above the magnetite and in the hematite layer, the growth stresses depend initially on volumetric strains and later on inner oxide formation and creep of the hematite.
\end{abstract}

Keywords Iron single crystal · Oxidation - Energy-dispersive diffraction . In situ stress analysis · Stress gradients

\section{Introduction}

The formation of oxide scales on metallic substrates exposed to corrosive environments and high temperatures is invariably accompanied by growth

C. Juricic $\cdot$ H. Pinto $(\bowtie) \cdot$ D. Cardinali

Max-Planck-Institut für Eisenforschung GmbH, Max-Planck-Strasse 1, 40237 Düsseldorf, Germany e-mail: h.pinto@mpie.de

\section{Klaus}

Technische Universität Berlin, Institut für Werkstoffwissenschaften und - technologien, ErnstReuter-Platz 1, 10587 Berlin, Germany

Ch. Genzel · A. R. Pyzalla

Helmholtz-Zentrum Berlin für Materialien und Energie (c/o BESSY), Albert-Einstein-Straße 15, 12489 Berlin, Germany 
incompatibilities. These mismatches give rise to internal stresses capable of deteriorating the shielding efficiency of those surface layers against the destructive reaction between the metal and the corrosive agents $[1,2]$.

The sources of growth stresses within oxide scales are manifold. Among the diverse models proposed over the past years [3], volumetric changes between the oxide formed and the metal consumed according to Pilling and Bedworth [4], the growth of new oxide in oxide grain boundaries [5-7] and epitaxial growth [8,9] appear to be the most relevant mechanisms.

In addition to growth strains, the crystallographic orientation of the substrate can also influence the oxidation kinetics [10-13]. The distinct oxidation behavior of single crystals might be associated therefore with particular internal stress states [14] resulting from preferential orientations of oxide growth. However, internal stresses have been mostly studied in oxide scales forming on polycrystalline substrates [15-18]. Under these conditions, the role of substrate orientation in the crystallographic texture of the oxides and therefore in the internal stresses of the oxide scale can not be evidenced. Owing to the diversity of mechanisms for stress generation in oxide scales, the time dependence of growth stresses has also been modeled only for cases where an individual oxide phase grows on the metallic substrate without considering possible orientation relationships between substrate and oxide [19, 20].

The present work is therefore devoted to the influence of substrate orientation and preferential orientation of oxide growth on the internal stress state of oxide scales. To this end, the oxidation behavior of a pure iron single crystal with (110) surface orientation is compared to the one of a polycrystalline Armco iron. Here the low-temperature oxidation regime of $\alpha$-iron was studied at $450{ }^{\circ} \mathrm{C}$, where thin, more protective two-phase oxide scales grow on iron substrates [21-26].

The microstructure evolution in the iron oxide scales was followed ex situ by scanning electron microscopy (SEM) and electron backscatter diffraction (EBSD). Regarding in situ studies of oxidation the advent of third generation synchrotron radiation sources opened up new possibilities, particularly with respect to strain measurements [27]. The oxidation behavior at $450{ }^{\circ} \mathrm{C}$ was therefore studied in situ by energy-dispersive (ED) X-ray diffraction (XRD) with synchrotron radiation. ED diffractograms recorded at fixed sample and detector positions provide a multitude of diffraction lines simultaneously. This reduces considerably the data acquisition times [27, 28], hence enabling simultaneous texture and stress studies in oxide scales. With respect to the lack of information on the gradients of growth stresses during oxidation, stress analyses by ED diffraction further benefit from the different energies $\mathrm{E}_{\mathrm{hkl}}$ of the individual diffraction lines. This allows for in situ depthresolved stress studies in the near-surface zone [29].

\section{Experimental Details}

\section{Ex Situ Oxidation and Thermogravimetry}

Strain annealed single crystals of pure iron with (110) surfaces were supplied with $4 \mathrm{~N}$ purity by Mateck GmbH, Jülich, Germany. The as-received iron single crystals 
Table 1 Chemical composition of Armco-iron

\begin{tabular}{|c|c|c|c|c|c|c|c|c|c|c|c|}
\hline \multicolumn{12}{|c|}{ Chemical composition of Armco iron [\%] } \\
\hline \multicolumn{12}{|c|}{ Tolerances after DIN 1013} \\
\hline $\mathrm{C}$ & $\mathrm{Mn}$ & $\mathrm{P}$ & $\mathrm{S}$ & $\mathrm{Cu}$ & $\mathrm{N}$ & $\mathrm{Sn}$ & $\mathrm{Si}$ & $\mathrm{Al}$ & $\mathrm{Cr}$ & Mo & $\mathrm{Ni}$ \\
\hline 0.005 & 0.073 & 0.005 & 0.005 & 0.011 & 0.006 & 0.008 & 0.018 & 0.04 & 0.017 & 0.003 & 0.021 \\
\hline
\end{tabular}

were discs of $8 \mathrm{~mm}$ diameter and $1 \mathrm{~mm}$ thickness. The sample surfaces were polished with a roughness of $<0.03$ micron and an orientation accuracy of $<0.1^{\circ}$.

Pure iron polycrystals (Armco-iron) were supplied by REMAG AG, Mannheim, Germany. Their chemical composition is listed in Table 1. The average grain size is $25 \mu \mathrm{m}$. The as-received hot-rolled Armco-iron bar with a $20 \mathrm{~mm}$ diameter was turned to $8 \mathrm{~mm}$ diameter and cut into $1 \mathrm{~mm}$ thick discs. The sample surfaces were prepared by grinding and polishing with $\mathrm{SiC}$-paper and diamond paste. Colloidal silica with $0.25 \mu \mathrm{m}$ grain size was used as a final polishing stage.

Samples for ex situ diffraction and microstructure studies were oxidized at $450{ }^{\circ} \mathrm{C}$ for $1 \mathrm{~h}, 5 \mathrm{~h}$, and $10 \mathrm{~h}$ in artificial air $\left(20 \% \mathrm{O}_{2} ; 80 \% \mathrm{~N}_{2}\right)$ at ambient pressure using a Setaram TGA 92 thermal balance. The heating rate was $1.4 \mathrm{~K} / \mathrm{s}$.

Microstructure and Texture Studies

\section{Sample Preparation}

the oxidized specimens were sputtered with gold and nickel ( $15 \mu \mathrm{m}$ layer thickness) to protect the oxide scale during mechanical preparation and to enhance the electrical conductivity around the oxides. Sample cross-sections were prepared by grinding with SiC-paper, then lapping with diamond films $(6,3,1,0.5,0.25 \mu \mathrm{m})$. Final polishing was carried out using colloidal silica $(0.25 \mu \mathrm{m})$.

\section{EBSD}

The oxide scales were characterized using a SEM JEOL JSM6490 equipped with a TSL-EBSD system. All EBSD maps were analyzed with respect to phase identification, grain size distribution and crystallographic texture using the OIM 5.22 software.

\section{In Situ ED Diffraction Studies}

In situ oxidation experiments were performed with an iron polycrystal and a single crystal at $450{ }^{\circ} \mathrm{C}$ in atmospheric air using ED diffraction at the Materials Science Beamline EDDI of the Helmholtz Zentrum Berlin at the synchrotron storage ring BESSY and an air-cooled resistance furnace developed in-house, which enables heating-up rates of $1000 \mathrm{~K} / \mathrm{min}$ and stable temperatures of up to $1000{ }^{\circ} \mathrm{C}$. The oxidation temperature remained constant within $\pm 10^{\circ} \mathrm{C}$. 
In the ED diffraction experiment the sample is illuminated by the polychromatic white primary beam originally produced at the synchrotron photon source. Thus, for each diffractometer setting $(\omega, \varphi, \psi)$ of the sample (see Fig. 1 for the definition of the instrumental angles $\omega, \varphi$ and $\psi$ of a four-circle diffractometer) all diffraction lines are generated simultaneously by different radiation energies at a fixed $2 \theta$-position. The result of such a measurement are ED diffractograms where the diffraction lines appear as a function of the energy (see Fig. 2). At EDDI the highest
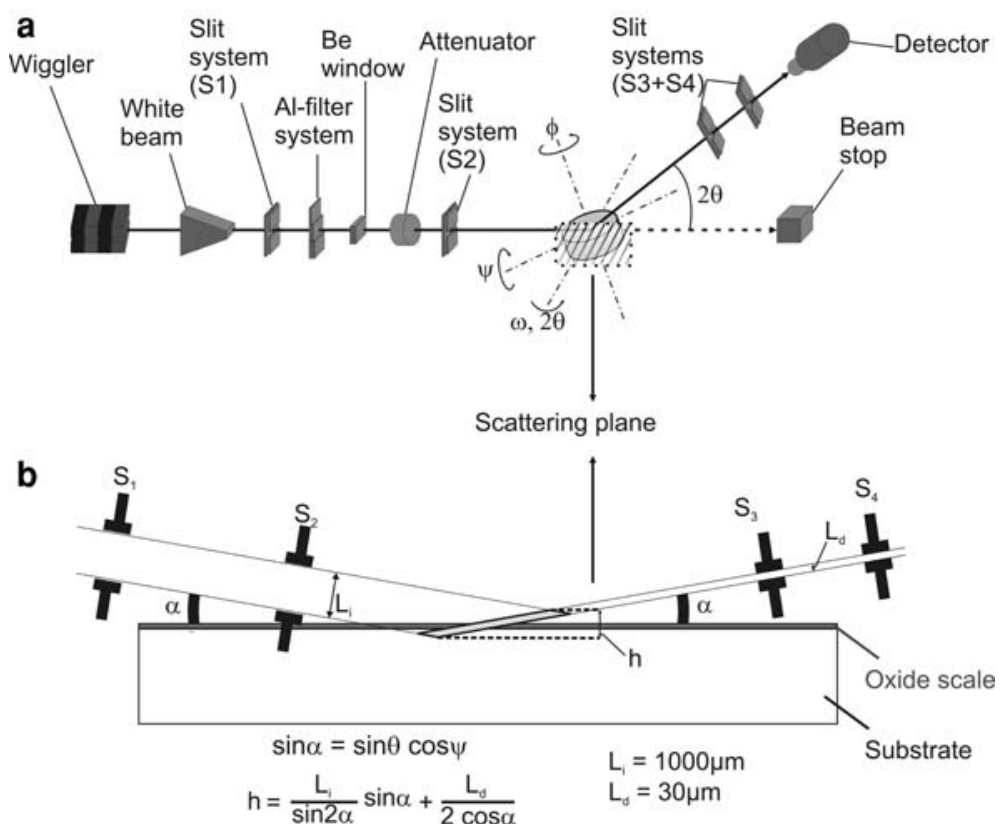

Fig. 1 Schematic layout of the main components at the EDDI beamline (a). Location and geometry of the gauge volume used for the stress analyses with energy-dispersive synchrotron x-ray diffraction (b)

Fig. 2 Energy-dispersive synchrotron X-ray diffractograms from the growing iron oxide layer recorded during oxidation at $450{ }^{\circ} \mathrm{C}$

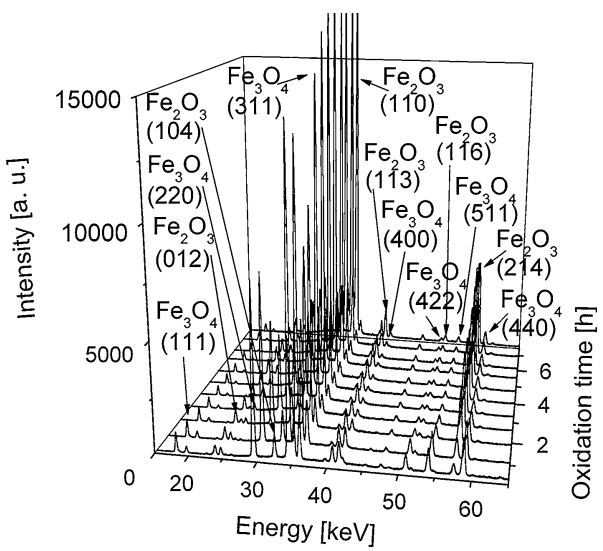


photon fluxes in the continuous energy spectrum are observed for energies between 15 and $85 \mathrm{keV}$ [28], which represent consequently the energy range of the assessable diffraction lines.

The relationship for ED diffraction (Eq. 2) between the lattice spacing $d_{h k l}$ and the corresponding energy of the diffraction line $\mathrm{E}_{(\mathrm{hkl})}$ can be derived from Bragg's law by inserting the energy relation given by Eq. 1:

$$
\begin{gathered}
\mathrm{E}=\mathrm{h} v=\frac{\mathrm{hc}}{\lambda} \\
\mathrm{d}_{(\mathrm{hkl})}=\frac{\mathrm{hc}}{2 \sin \theta} \frac{1}{\mathrm{E}_{(\mathrm{hkl})}}=\text { const. } \frac{1}{\mathrm{E}_{(\mathrm{hkl})}}
\end{gathered}
$$

where $\mathrm{h}$ is Planck's constant, $\mathrm{c}$ the velocity of light, and $\lambda$ the wavelength giving rise to the ED diffraction line (hkl).

For the present investigation the $2 \theta$-angle was fixed at $8^{\circ}$ and the symmetric diffraction mode was applied with the $\omega$-rotation of the sample being set to half of the diffraction angle $2 \theta(\omega=\theta)$. The in situ measurements were conducted during the oxidation of an iron polycrystal and a single crystal following the $\sin ^{2} \psi$ measurement strategy with nine $\psi$-tilts between 18 and $72^{\circ}$.

Since each ED diffraction line results from different photon energy contained in the white energy spectrum, the penetration depth $\tau_{(\mathrm{hkl})}$ does not only depend on the measurement angles $2 \theta$ and $\psi$ but becomes also a function of the reflection considered:

$$
\tau_{(\mathrm{hkl})}=\frac{1}{2 \mu_{(\mathrm{hkl})}\left(\mathrm{E}_{(\mathrm{hkl})}\right)} \cdot \sin \theta \cdot \cos \psi
$$

where $\mu_{(\mathrm{hkl})}$ is the linear absorption coefficient dependent on the photon energy $\mathrm{E}_{(\mathrm{hkl})}, \theta$ is half of the diffraction angle chosen and $\psi$ is the tilt angle. In case of a $\sin ^{2} \psi$-measurement, an average penetration depth $\left\langle\tau_{(\mathrm{hkl})}\right\rangle$ can be thus assigned to each individual diffraction line:

$$
\left\langle\tau_{(\mathrm{hkl})}\right\rangle=\frac{\tau_{(\mathrm{hkl})}\left(\psi_{\min }\right)+\tau_{(\mathrm{hkl})}\left(\psi_{\max }\right)}{2}
$$

Considering the experimental setup used and the available energy range of $15-85 \mathrm{keV}$ at EDDI, the maximum range of penetration depths, which can be probed simultaneously within an iron oxide scale, is of $1-85 \mu \mathrm{m}$. The average penetration depth $\left\langle\tau_{(\mathrm{hkl})}\right\rangle$ associated with a certain diffraction line will depend, however, on its exact energy position.

Figure 1a displays the layout of the EDDI beamline. The geometry and location of the gauge volume is illustrated in Fig. 1b. The gauge volume was defined by primary slits $(\mathrm{S} 1, \mathrm{~S} 2)$ of $1 \times 1 \mathrm{~mm}^{2}$ and secondary slits $(\mathrm{S} 3, \mathrm{~S} 4)$ of $30 \mu \mathrm{m} \times 5 \mathrm{~mm}$. The position of the sample surface was realigned after each analysis by measuring the diffracted intensity, when moving the sample across the gauge volume. The acquisition time for recording an ED diffractogram at each $\psi$-tilt was $2.5 \mathrm{~min}$. Considering the motor movements, $28 \mathrm{~min}$ were required for performing an entire $\sin ^{2} \psi$-measurement. 


\section{Texture Analyses}

Assuming the formation of a fiber texture in the surface normal direction, (111), (220), (400), (422), and (511) pole figures of magnetite were generated from the measured intensity distributions as a function of the $\psi$-angle using a rotational symmetry regarding the surface normal. Inverse pole figures were then computed using the BEARTEX software [30] in order to follow the evolution of the fiber component in the magnetite sub-layer.

\section{Stress Studies}

The phase-specific stresses evolving during oxidation were also evaluated from the in situ oxidation experiments according to the $\sin ^{2} \psi$-method [31]. The penetration depth $\tau_{(\mathrm{hkl})}$ as given by Eq. 3 has a physical meaning only for thick samples, since in case of thin surface layers it can become much larger than the layer thickness. In those cases one needs to determine, where the diffraction information comes from. To this end, the concept of effective information depth $\tau^{\text {eff }}$ was established for diffraction studies of thin films, which may be interpreted as the contribution of each sub-layer $d z$ at some depth $z$ beneath the scale surface to the recorded diffraction line weighted by an exponential attenuation factor. Thus, in the ED diffraction experiment, each reflection of the oxide scale corresponding to different radiation energy stems from a distinct effective information depth, which is defined by [32]:

$$
\tau_{(\mathrm{hkl})}^{\text {eff }}=\frac{\int_{0}^{D} \mathrm{z} \cdot \mathrm{e}^{-\frac{\mathrm{z}}{\tau}(\mathrm{hkl})} \mathrm{dz}}{\int_{0}^{\mathrm{D}} \mathrm{e}^{-\frac{\mathrm{z}}{\tau(\mathrm{hkl})}} \mathrm{dz}}=\tau_{(\mathrm{hkl})}-\frac{\mathrm{D} \mathrm{e}^{-\frac{\mathrm{D}}{\tau_{(\mathrm{hkl})}}}}{1-\mathrm{e}^{-\frac{\mathrm{D}}{\tau_{\text {(hkl) }}}}}
$$

where $\tau_{(\mathrm{hkl})}$ is the average penetration depth correspondent to a certain (hkl) diffraction line into an infinitely thick sample given by Eq. 3, and D is the layer thickness. As the energy of the diffraction line increases, the absorption decreases and the penetration depth $\tau_{(\mathrm{hkl})}$ increases. Thus, the ratio D/ $\tau_{(\mathrm{hkl})}$ in Eq. 5 decreases towards zero, leading the effective information depth $\tau_{(\mathrm{hkl})}^{\text {eff }}$ to approach the limit D/2 [32], when $\tau_{(\mathrm{hkl})}$ is much larger than the scale thickness. This implies that using this method the maximum achievable information depth will be half of the scale thickness.

The present approach for evaluating ED Diffraction data regarding long-range stress gradients corresponds to the 'Multi Wavelength' method used with Angle Dispersive Diffraction [28, 33, 34]. For the thicker magnetite layer, Eq. 5 yields significantly different effective information depths for the assessable diffraction lines, enabling therefore the in situ evaluation of internal stress gradients in the magnetite sub-layer.

Due to the columnar oxide growth and the linear $\sin ^{2} \psi$-curves observed, the phase-specific diffraction elastic constants (DEC) were calculated for each examined (hkl) lattice plane based on the Reuss approach [35, 36]. The single crystal elastic constants of magnetite and hematite, which are necessary for DECcalculation, are available in [37] for RT. 


\section{Results}

\section{Oxidation Kinetics}

The oxidation temperature $450{ }^{\circ} \mathrm{C}$ was reached after $5 \mathrm{~min}$ in the thermal balance. Figure 3 compares the time dependence of the square of the mass gain for the $\alpha$-iron single crystal with (110) surface orientation and the polycrystalline Armco iron.

The oxidation kinetics in both cases is characterized by a continually decreasing parabolic kinetics, where three major stages can be distinguished. After heating to $450{ }^{\circ} \mathrm{C}$ the oxidation kinetics of both substrates exhibits a short period of high oxidation rates (Stage 1). This first stage takes $10 \mathrm{~min}$ for the polycrystalline and 15 min for the single crystal substrate. A transition range (Stage 2) occurs for both substrates during the next $3 \mathrm{~h}$ where the parabolic oxidation kinetics decelerates. After $3 \mathrm{~h}$ of oxidation a third stage (Stage 3) is observed with a growth rate considerably slower than in stage 1 .

The parabolic rate constants $k_{\mathrm{p}}$ determined from the slopes of the curves in Fig. 3 for stages 1 and 3 are listed in Table 2, revealing that the oxidation rate on the polycrystalline substrate is faster than on the single crystal substrate within the first hour of oxidation. Afterwards the oxidation rate of the single crystal substrate becomes slightly faster. The oxide scale thicknesses determined on cross-sections of oxidized iron single crystals and polycrystals after different oxidation times are listed in Table 3.

\section{Characterization of Microstructure in the Iron Oxide Scales}

The microstructure of the oxide scales was studied by SEM and EBSD after $1 \mathrm{~h}, 5 \mathrm{~h}$ and $10 \mathrm{~h}$ of oxidation in the thermal balance (Figs. 4, 5). The average grain

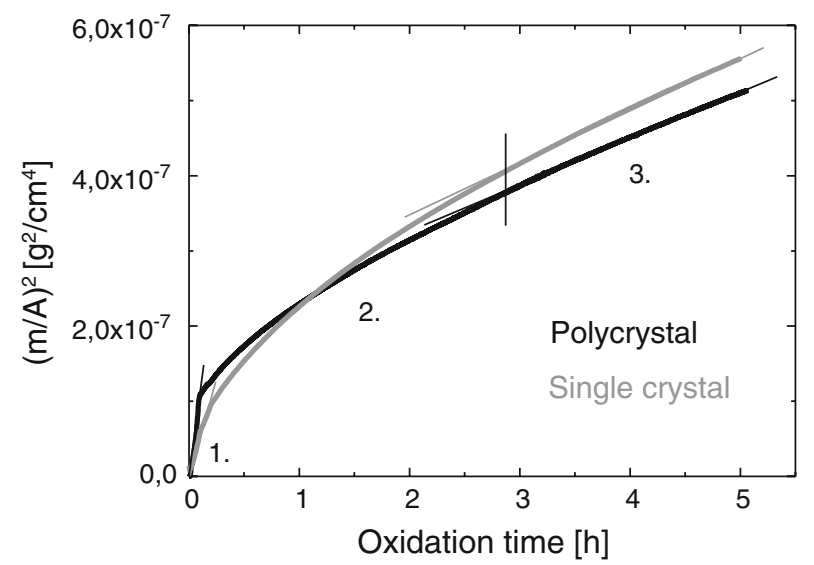

Fig. 3 Square of the mass gain for an iron single crystal with (110) surface and an Armco iron polycrystal during oxidation in artificial air at $450{ }^{\circ} \mathrm{C}$ as a function of the oxidation time 
Table 2 Parabolic rate constants during oxidation at $450{ }^{\circ} \mathrm{C}$

Parabolic rate constants during oxidation at $450{ }^{\circ} \mathrm{C}$

\begin{tabular}{lll}
\hline & Region $1\left(\mathrm{~g} \mathrm{~cm}^{-2} \mathrm{~s}^{-1}\right)$ & Region $3\left(\mathrm{~g}^{2} \mathrm{~cm}^{-4} \mathrm{~s}^{-1}\right)$ \\
\hline Polycrystal & $3.00 \times 10^{-10}$ & $1.71 \times 10^{-11}$ \\
Single crystal & $1.33 \times 10^{-10}$ & $1.91 \times 10^{-11}$ \\
\hline
\end{tabular}

Table 3 Thicknesses of the iron oxide scales after different oxidation times at $450{ }^{\circ} \mathrm{C}$ in artificial air at ambient pressure

\begin{tabular}{llll}
\hline Thickness of the iron oxide scale after different oxidation times at $450{ }^{\circ} \mathrm{C}(\mu \mathrm{m})$ & \\
\hline & $1 \mathrm{~h}$ & $5 \mathrm{~h}$ & $10 \mathrm{~h}$ \\
\hline On polycrystal: oxide scale in total & $2.64 \pm 0.2$ & $6.91 \pm 0.3$ & $8.22 \pm 0.3$ \\
Magnetite sub-layer & $2.43 \pm 0.2$ & $6.63 \pm 0.3$ & $7.87 \pm 0.3$ \\
Hematite top-layer & $0.21 \pm 0.02$ & $0.28 \pm 0.04$ & $0.35 \pm 0.04$ \\
On single crystal: oxide scale in total & $2.65 \pm 0.1$ & $7.69 \pm 0.2$ & $8.83 \pm 0.2$ \\
Magnetite sub-layer & $2.44 \pm 0.1$ & $7.44 \pm 0.3$ & $8.52 \pm 0.2$ \\
Hematite top-layer & $0.21 \pm 0.02$ & $0.25 \pm 0.03$ & $0.31 \pm 0.04$ \\
\hline
\end{tabular}

diameter in the polycrystalline iron substrate was $24 \mu \mathrm{m}$, which corresponds to an average grain area of $437 \mu \mathrm{m}^{2}$.

\section{Oxide Scales on Iron Polycrystals}

After $1 \mathrm{~h}$ of oxidation at $450{ }^{\circ} \mathrm{C}$ an oxide scale of $2.6 \mu \mathrm{m}$ thickness grows on Armco iron. It mainly consists of a magnetite $\left(\mathrm{Fe}_{3} \mathrm{O}_{4}\right)$ layer. Hematite $\left(\mathrm{Fe}_{2} \mathrm{O}_{3}\right)$

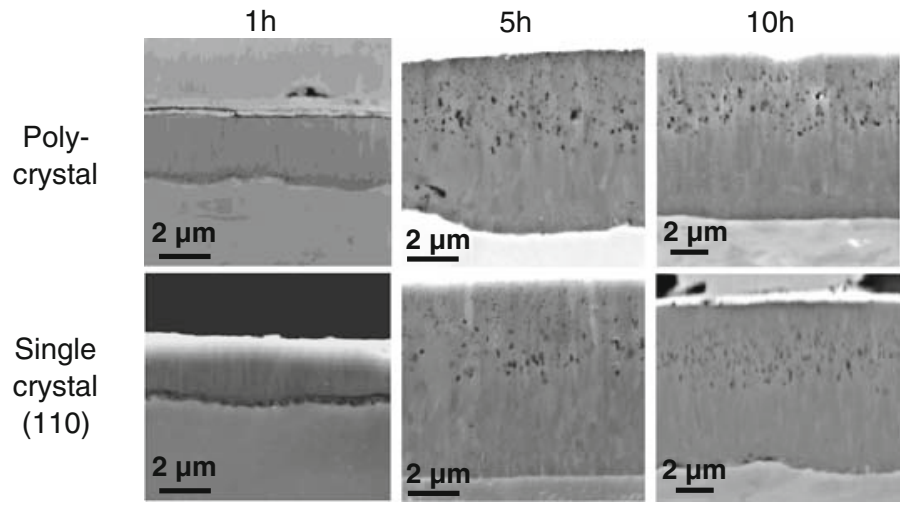

Fig. 4 Scale cross-sections (SEM) as a function of the oxidation time 


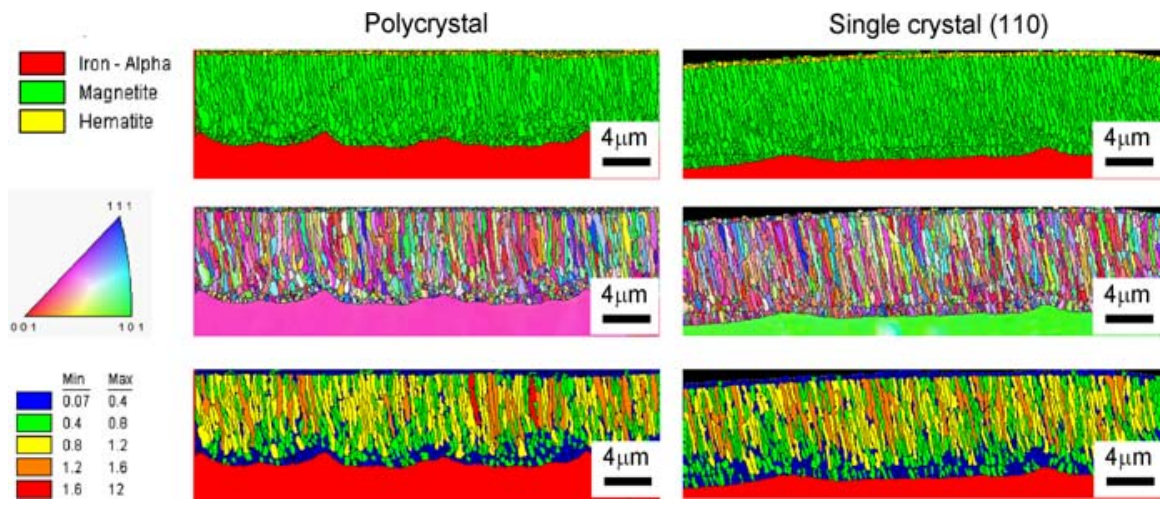

Fig. 5 EBSD-maps of the oxide scales on iron polycrystals and single crystal with (110) surface after $5 \mathrm{~h}$ oxidation at $450{ }^{\circ} \mathrm{C}$ : phase composition, grain orientation, and grain size maps

builds up on top of the scale with only $0.21 \mu \mathrm{m}$ layer thickness. With ongoing oxidation, magnetite is observed to grow much faster than the topmost hematite layer. The thickness of the magnetite sub-layer on the polycrystalline substrate reaches about $6.6 \mu \mathrm{m}$ after $5 \mathrm{~h}$ and $7.9 \mu \mathrm{m}$ after $10 \mathrm{~h}$ of oxidation. The hematite sub-layer, on the other hand, is only about $0.28 \mu \mathrm{m}$ thick after $5 \mathrm{~h}$ and $0.35 \mu \mathrm{m}$ after $10 \mathrm{~h}$.

The grain morphology is predominantly columnar in magnetite with increasing oxidation times, whereas it remains equiaxial in hematite (Fig. 6a). EBSD reveals after $5 \mathrm{~h}$ of oxidation an average grain area of $0.26 \mu^{2}$ in magnetite grown on the polycrystalline substrate. The average grain area of the hematite ranges between 0.01 and $0.02 \mu \mathrm{m}^{2}$. The aspect ratio of the magnetite grains amounts to 0.31 , whereas the average intercept length in magnetite is $0.63 \mu \mathrm{m}$.

SEM-EBSD studies further show a seam of small globular magnetite grains located at the interface with the polycrystalline substrate since $1 \mathrm{~h}$ of oxidation (Figs. 4, 5). The thickness of this globular seam ranges between 0.5 and $1 \mu \mathrm{m}$ after $5 \mathrm{~h}$, and between 0.95 and $1.4 \mu \mathrm{m}$ after $10 \mathrm{~h}$ of oxidation. The oxide scale grows initially intact on the iron polycrystal, as it can be derived from SEM-micrographs of the oxide layer after $1 \mathrm{~h}$ of oxidation (Fig. 4). With increasing oxidation time, voids appear along the interface with the globular seam and in the outer region of the magnetite layer, thus reducing the contact area of the oxide scale to the substrate (Fig. 6b). Further oxidation leads to coarsening of the voids resulting in a vast number of pores in the upper half of the oxide layer. The entire scale is also nonuniform in thickness, therefore evolving a wavy pattern at the interface with the substrate.

\section{Oxide Scales on Iron Single Crystals with (110) Surface Orientation}

After $1 \mathrm{~h}$ of oxidation at $450{ }^{\circ} \mathrm{C}$ the iron oxide scale on the single crystal substrate is $2.7 \mu \mathrm{m}$ thick. It also consists of a thicker magnetite $\left(\mathrm{Fe}_{3} \mathrm{O}_{4}\right)$ layer 

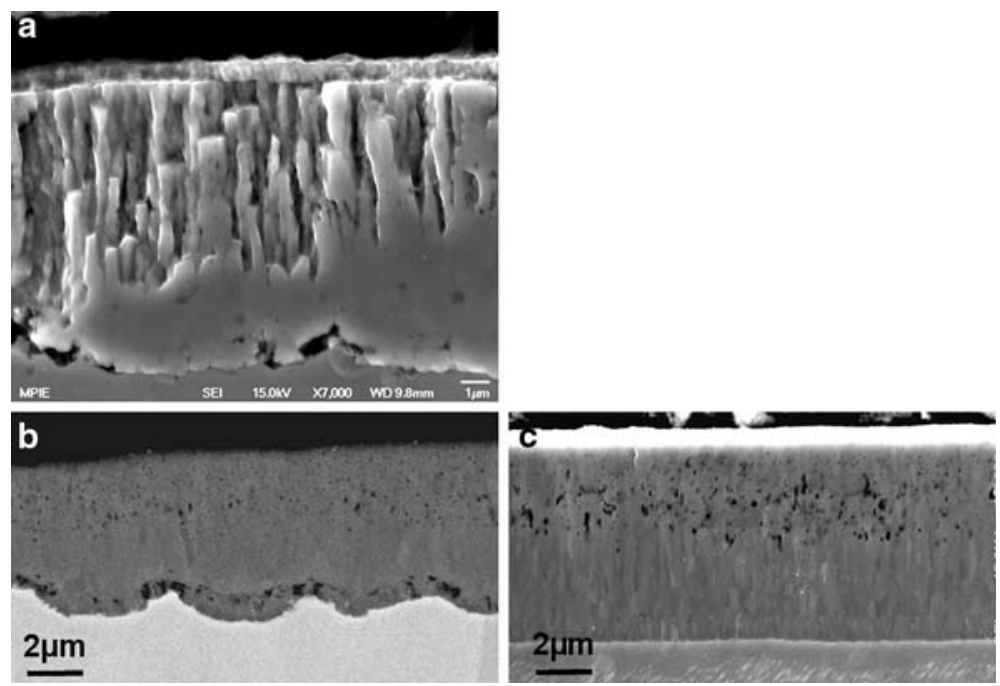

Fig. 6 Cross sections of iron oxide layers. Fractured oxide layer with columnar grain growth in the magnetite layer and small hematite grains in the topmost layer (a). Oxide layer on iron polycrystals (b) and on iron single crystal (c)

and a very thin hematite $\left(\mathrm{Fe}_{2} \mathrm{O}_{3}\right)$ layer of about $0.2 \mu \mathrm{m}$ thickness on top of the scale. As in the oxide scale on polycrystalline iron, the growth rate of magnetite is significantly faster than that of the hematite. Thus, the thickness of the magnetite layer reaches $7.4 \mu \mathrm{m}$ after $5 \mathrm{~h}$ and $8.5 \mu \mathrm{m}$ after $10 \mathrm{~h}$ of oxidation. The topmost hematite layer grows up to about $0.3 \mu \mathrm{m}$ thickness after $10 \mathrm{~h}$ of oxidation.

The grain morphology is similar to that observed in the oxide scale on the iron polycrystal. Magnetite is predominantly columnar, whereas hematite has equiaxed grains (Fig. 6a). $5 \mathrm{~h}$ of oxidation leads to an average grain size of $0.19 \mu \mathrm{m}^{2}$ in magnetite. Hematite has average grain sizes between 0.01 and $0.02 \mu \mathrm{m}^{2}$. The aspect ratio of the magnetite grains on the iron single crystal $(0.33)$ is also similar to that observed in the oxidized polycrystal. The magnetite layer on the single crystal substrate has, however, an average intercept length of $0.33 \mu \mathrm{m}$ which is significantly smaller than in magnetite on Armco iron.

Magnetite also evolves a duplex layer on the single crystal after $1 \mathrm{~h}$ of oxidation (Figs. 4, 5). The globular seam has a thickness similar to that observed on the polycrystalline substrate, i.e. between 0.5 and $1 \mu \mathrm{m}$ after $5 \mathrm{~h}$, and between 0.95 and $1.4 \mu \mathrm{m}$ after $10 \mathrm{~h}$. The magnetite layer appears to have a better adherence to the single crystal substrate. It also develops a wavy pattern at the interface with the substrate, however, over much longer distances than observed in the scale grown on Armco iron (Fig. 5). Only a few pores can be detected in the upper regions of the magnetite layer after $5 \mathrm{~h}$ of oxidation. 
Texture Analyses by EBSD and In Situ ED Diffraction

\section{Ex Situ EBSD}

Figure 7 displays inverse pole figures of the inner and outer magnetite layers after $1 \mathrm{~h}$ of oxidation. Magnetite grows on the iron polycrystal without a significant preferential orientation. On the single crystal, however, magnetite appears to follow the out-of-plane orientation of the substrate, therefore evolving a $\{110\}$ fiber texture in the direction of the surface normal. The texture strength is higher for the inner than for the outer layer. An in-plane orientation relationship between magnetite and the iron single crystal can not be observed.

The crystallographic texture of magnetite changes with increasing oxidation time. The inverse pole figures of magnetite with respect to the surface normal direction obtained after $5 \mathrm{~h}$ of oxidation of the single crystal and $10 \mathrm{~h}$ of the polycrystal at $450{ }^{\circ} \mathrm{C}$ are shown in Fig. 8. The polycrystalline substrate requires longer oxidation times to evolve clear $\{001\}$ fiber textures in comparison with the iron single crystal. The texture strength becomes higher for the columnar zone than for the globular seam.

Hematite (Fig. 9) grows on both substrates with similar textures. The texture strength is nearly the same for the iron polycrystal and single crystal. The $\{0001\}$ basal planes of the hematite are nearly perpendicular to the interface with magnetite. Their in-plane orientation is further characterized by a double component where the individual poles are turned about $60^{\circ}$ with respect to each other. The $\{1-210\}$ and $\{1-100\}$ prismatic planes lie nearly parallel to the magnetite surface, thus building

Iron single crystal

substrate after $1 \mathrm{~h}$

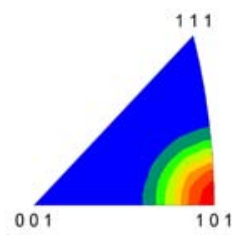

Polycrystalline

substrate after $1 \mathrm{~h}$

Texture
index
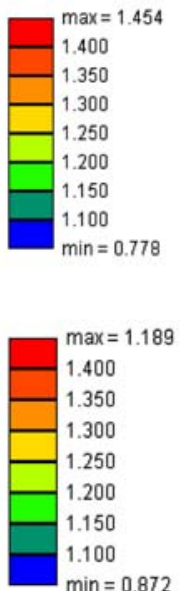

Magnetite:

Globular seam
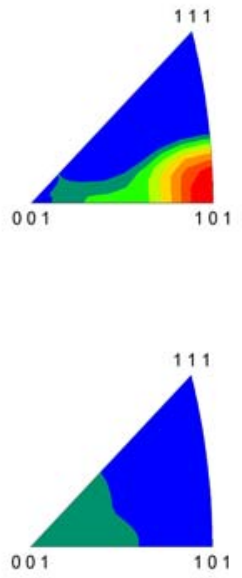

Magnetite:

Columnar grains
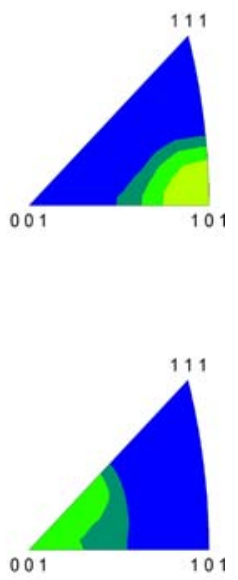

Fig. 7 Inverse pole figure of the iron single crystal; inverse pole figures of the duplex magnetite layers grown on iron single crystal and polycrystals after oxidation at $450{ }^{\circ} \mathrm{C}$ for $1 \mathrm{~h}$ 


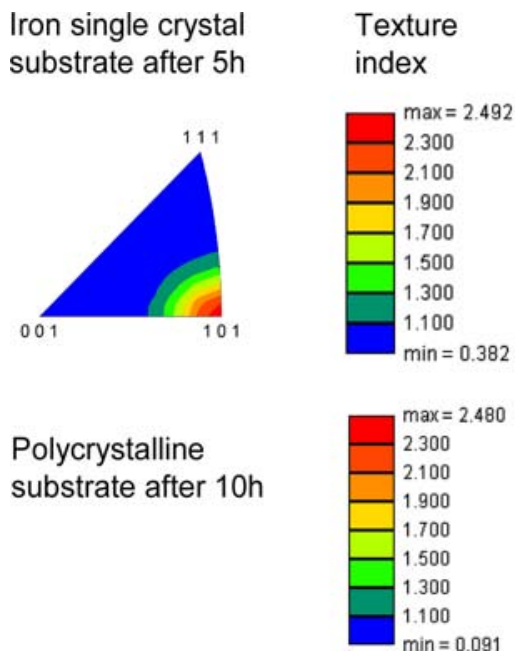

\section{Magnetite: \\ Globular seam}
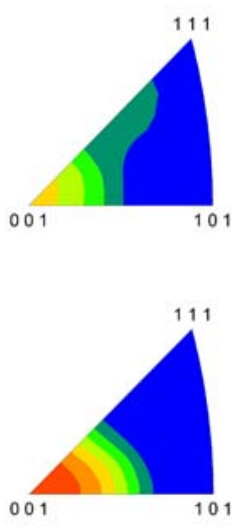

Magnetite:

Columnar grains
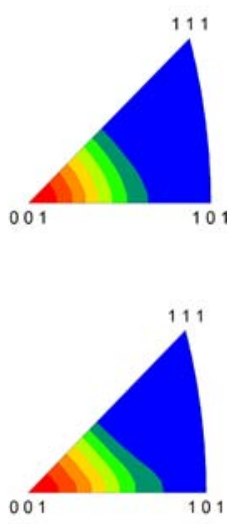

Fig. 8 Inverse pole figure of the iron single crystal; inverse pole figures of the duplex magnetite layers grown on iron single crystal for $5 \mathrm{~h}$ and polycrystal after oxidation at $450{ }^{\circ} \mathrm{C}$ for $10 \mathrm{~h}$

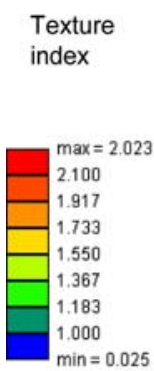

\section{Hematite on iron single crystal substrate}
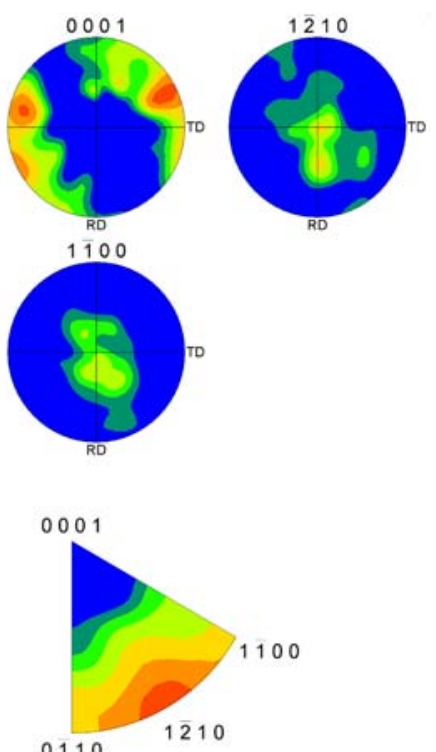

Hematite on iron polycrystalline substrate
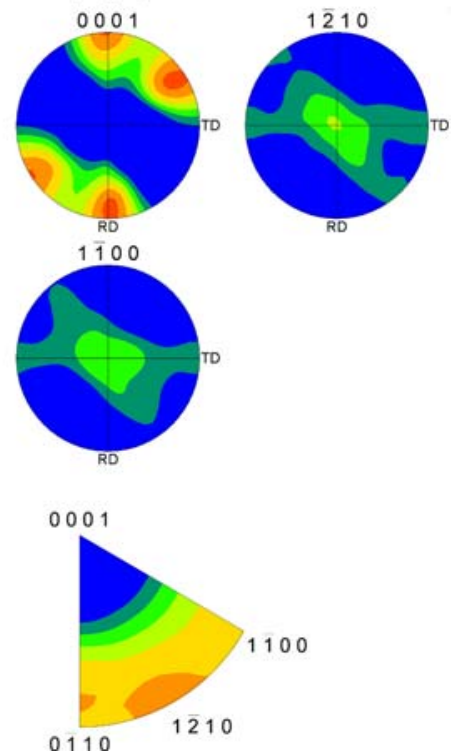

Fig. 9 Pole figures and inverse pole figures of the hematite top-layer on iron single crystal and polycrystals after oxidation at $450{ }^{\circ} \mathrm{C}$ for $5 \mathrm{~h}$

the fiber axis along the surface normal direction. This type of texture is in accordance with the cross-hatched orientation of the hematite platelets observed on top of the magnetite layer (Fig. 10a). 

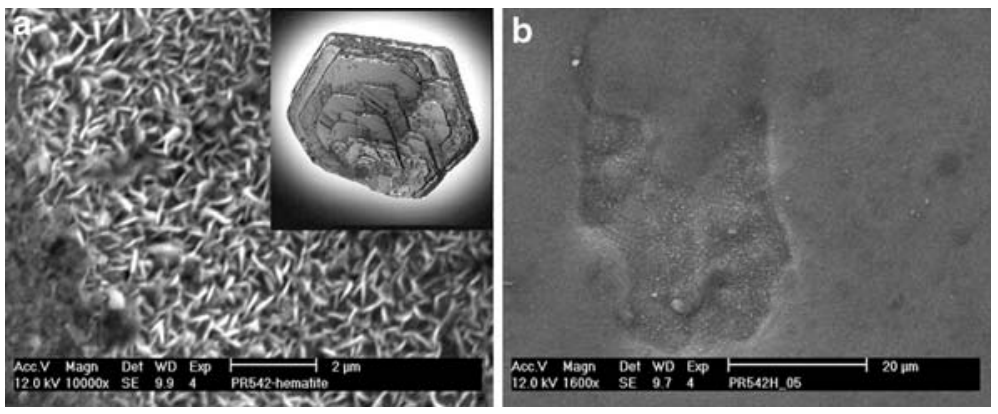

Fig. 10 Top-views of an oxide scale grown on iron polycrystals after oxidation at $450{ }^{\circ} \mathrm{C}$ for $10 \mathrm{~h}$. Detail-image from the hematite platelets (a), and overview-image from a continuous hematite layer (b)

\section{In Situ ED Diffraction}

The ED diffractograms of iron oxide scales growing at $450{ }^{\circ} \mathrm{C}$ show several well-developed magnetite reflections-(111), (220), (400), (422) and (511)(Fig. 2). With the knowledge that magnetite evolves fiber textures since the early oxidation stages, simplified texture analyses were carried out based on rotational symmetric pole figures generated from the distributions of integrated intensities for each reflection as a function of the tilting angle $\psi$. This allowed for an in situ study of the average texture component of magnetite in the direction of the surface normal.

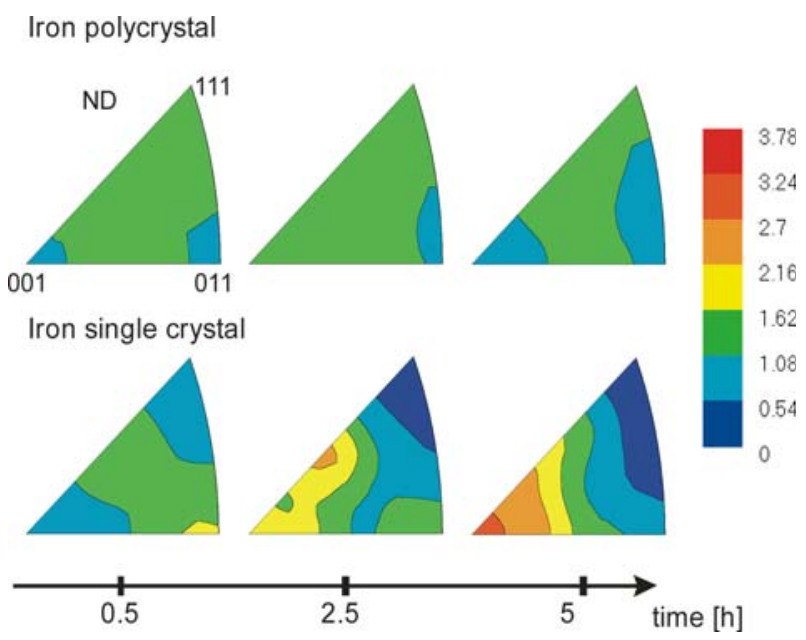

Fig. 11 Inverse pole figures of magnetite on iron single crystal and polycrystals obtained from the in situ ED diffraction during oxidation at $450{ }^{\circ} \mathrm{C}$ 
Figure 11 displays the time evolution of the crystallographic fibers of magnetite for the single crystal and polycrystalline substrates. The magnetite layer growing on Armco iron exhibits no clear fiber component during the $5 \mathrm{~h}$ of oxidation. On the other hand, the texture strength in the magnetite layer growing on the single crystal substrate is higher. Magnetite appears initially to grow with a weak $\{110\}$ fiber which after $2 \mathrm{~h}$ of oxidation turns into the persistent $\{001\}$ fiber component.

\section{In Situ Stress Analyses by ED Diffraction}

Since the ED diffraction lines are generated by different radiation energies (see Fig. 2), they penetrate the oxide scale differently. According to Eqs. 2 and 3, the higher the reflection order $\left(\mathrm{h}^{2}+\mathrm{k}^{2}+\mathrm{l}^{2}\right)$, the larger is the correspondent penetration depth in ED diffraction experiments.

The penetration depth associated with the (012), (104), (113), and (116) reflections of the hematite is much larger than its maximum layer thickness $(1.1 \mu \mathrm{m})$. Thus, the stress values of the hematite in Fig. 13a and $\mathrm{b}$ are representative averages for the entire topmost layer during the whole experiment.

In contrast, the average penetration depth $\left\langle\tau_{(\mathrm{hkl})}\right\rangle$ for non-overlapping magnetite reflections given by Eq. 4 varies between 1.8 and $38 \mu \mathrm{m}$. These minimum and maximum values are associated with the first $\left(\mathrm{Fe}_{3} \mathrm{O}_{4}-111\right)$ and last $\left(\mathrm{Fe}_{3} \mathrm{O}_{4}-511\right)$ assessable diffraction lines, located at about 18 and $55 \mathrm{keV}$, respectively. Since these penetration depths are smaller or, at least, in the same order of magnitude of the maximum magnetite layer thickness on both substrates (about $29 \mu \mathrm{m}$ ), the internal stresses determined from the (111), (220), (400), (422), and (511) reflections of magnetite can be assigned to different layer depths.

The information depth $\tau_{(\mathrm{hkl})}^{\text {eff }}$ given by Eq. 5 for different magnetite reflections varies with the oxidation time, as a result of the increasing layer thickness. Figure 12a displays the variation of the information depth for each individual magnetite reflection during the oxidation of the single crystal substrate. For the sake of comparison the $\tau_{\text {(hkl) }}^{\text {eff }}$-values are normalized with respect to the actual layer thickness $\mathrm{D}_{\text {Magnetite, }}$ which was estimated based on the $29 \mu \mathrm{m}$ layer thickness after $10 \mathrm{~h}$ of oxidation and a single parabolic growth rate. At the beginning of the in situ oxidation cycle the different diffraction lines of magnetite cover therefore a portion of $25-48 \%$ of the magnetite layer thickness, whereas in the last measurement they represent $5-45 \%$ of the layer thickness.

The $\sin ^{2} \psi$-curves for the hematite and magnetite reflections during oxidation at $450{ }^{\circ} \mathrm{C}$ are linear as exemplified in Fig. 12b. The principle of in situ depth-resolved stress analysis in the magnetite layer using EDXRD is illustrated in Fig. 12c. The $\sin ^{2} \psi$-curves obtained from different diffraction lines of magnetite exhibit distinct slopes. This implies that the growth stresses in the magnetite layer change with the effective information depth, thus characterizing the existence of stress gradients along the layer thickness.

The present approach for assessing the gradients of growth stresses relies on the macroscopic isotropy of the considered phase. The distinct strain response of the examined (hkl) lattice planes is thus taken into account in the stress determination by applying the correspondent (hkl)-dependent DEC. This assumption holds for 
Fig. 12 Effective information depths of different magnetite reflections as a function of the oxidation time (a). Typical d- $\sin ^{2} \psi$-curves obtained during in situ stress analyses (b). $\sin ^{2} \psi$ curves for different magnetite reflections showing distinct slopes, i.e. different stress values at different information depths (c). In the graphs D refers to the layer thickness, $d$ to the lattice spacing and a to the lattice parameter a
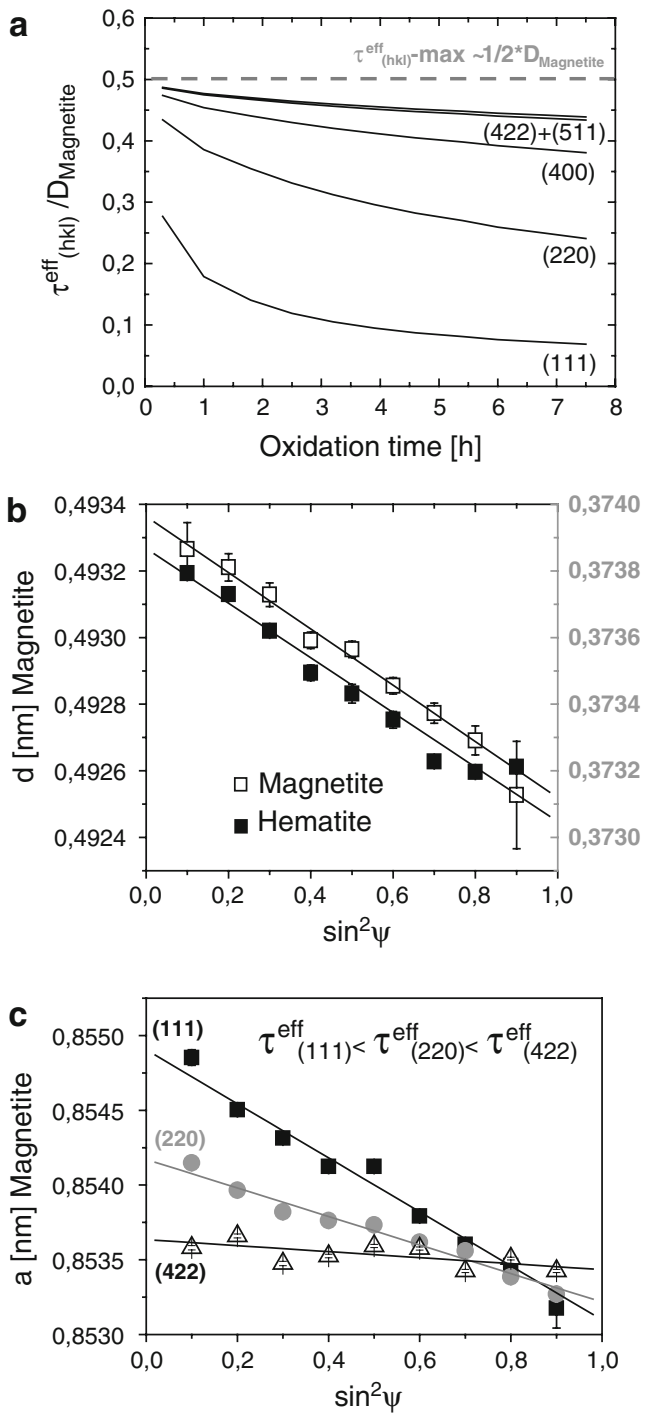

magnetite owing to the possibility of performing unrestricted lattice spacing measurements as a function of the $\psi$-tilt and the linearity of the $\sin ^{2} \psi$-curves obtained for different diffraction lines. For the same reasons, the procedure appears to apply to the hematite layer as well, in spite of its trigonal crystal lattice. However, the thickness of the topmost iron oxide layer has to increase significantly in order to accomplish different effective information depths for high-energy synchrotron X-rays.

The low elastic anisotropy reported for iron oxides in [38] further corroborates the proposed stress evaluation procedure. In the case of anisotropic phases, which are characterized by non-linear $\sin ^{2} \psi$-curves, the present ED method remains applicable; however, the orientation distribution function (ODF) and/or direction- 
dependent grain interaction models have to be taken into account in the evaluation of direction-dependent stress factors relating the measured strains to the internal stress state. For details on appropriate procedures for stress analysis in anisotropic surface layers, the reader is referred to [39, 40].

\section{Average Growth Stresses}

Figure 13a and $\mathrm{b}$ display the time evolution of the mean stress values obtained from averaging over all diffraction lines assessable, i.e. over different information depths, for the two iron oxides during 5-7 h of oxidation. On polycrystalline as well on single crystal substrates magnetite and hematite evolve compressive growth stresses (Fig. 13a, b). The hematite top-layers always exhibit higher growth stresses than magnetite.

The time-dependence of the growth stresses in magnetite and hematite is different for oxide scales growing on iron polycrystal and single crystal. The magnetite layer growing on Armco iron reveals low compressive stress values of about $-60 \mathrm{MPa}$ after $28 \mathrm{~min}$ and its value increases gradually to about $-270 \mathrm{MPa}$ after $5 \mathrm{~h}$. Hematite evolves compressive growth stresses of about $-270 \mathrm{MPa}$ within the first $28 \mathrm{~min}$ and this value persists during the entire oxidation.

On the single crystal substrate the compressive growth stresses of magnetite and hematite increase simultaneously during the first hour of oxidation up to values of about -340 MPa. With ongoing oxidation, these compressive stresses ease gradually.

\section{Gradient of Growth Stresses in Magnetite}

Figure 14 shows for both substrates how the stress-depth profiles obtained from each $\psi$-scan containing different magnetite reflections vary with the oxidation time. Each individual stress value in these plots stems therefore from a $\sin ^{2} \psi$-analysis performed using a different diffraction line of magnetite, as indicated in the first data set of each graphic. The $\mathrm{x}$-coordinate used for the individual stress values was
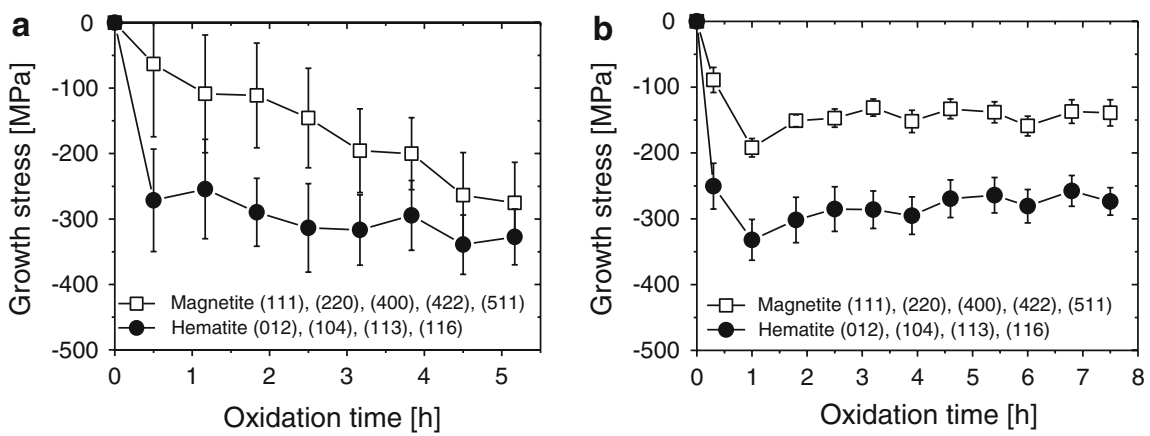

Fig. 13 Time evolution of average internal stresses during oxidation on iron polycrystals (a) and on iron single crystal (b). The error bars refer to the standard deviation between the stress values obtained for different (hkl) lines 
the distance to substrate, i.e. the estimated thickness of the magnetite layer at a certain time $\mathrm{D}_{\text {Magnetite }}(\mathrm{t})$ minus the effective information depth of the correspondent diffraction line $\tau_{\text {(hkl) }}^{\text {eff }}$. The implicit oxidation time scale is defined as to increase from left to right. With increasing oxidation times the magnetite layer thickens, leading the upper magnetite/hematite interface to increase its distance to the substrate. This was represented in Fig. 14 by blue vertical lines which move from left to right accompanying the in situ stress-depth profiles.

The stress depth-profiles of magnetite on polycrystalline as well on single crystal substrates are similar. Higher compressive stresses are observed next to the interface with the hematite layer. These compressive stresses decrease towards the substrate. This behavior persists during the entire oxidation. The stress gradient in magnetite on the polycrystalline substrate $(-100$ to $-800 \mathrm{MPa})$ is always much higher than on the single crystal substrate ( -90 to $-410 \mathrm{MPa})$.

Figure 15 displays in detail the stress situation near the interface with hematite. The individual stress values stem from the (111) reflection of magnetite which has the smallest penetration depth. The initial oxidation is governed by increasing stress
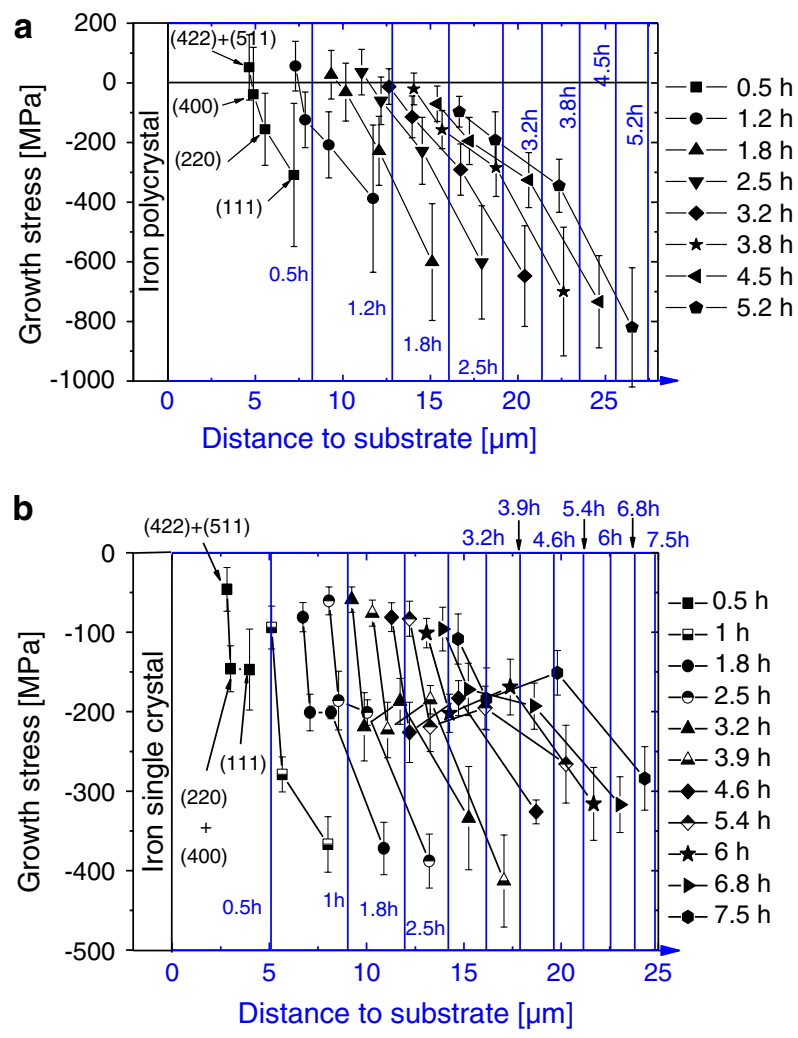

Fig. 14 Evolution of the internal stress distribution in the magnetite layer during the oxidation at $450{ }^{\circ} \mathrm{C}$ as a function of the distance to the iron polycrystalline (a) and to the iron single crystal substrate (b). The error bars refer to the regression errors of each $\sin ^{2} \psi$-analysis 


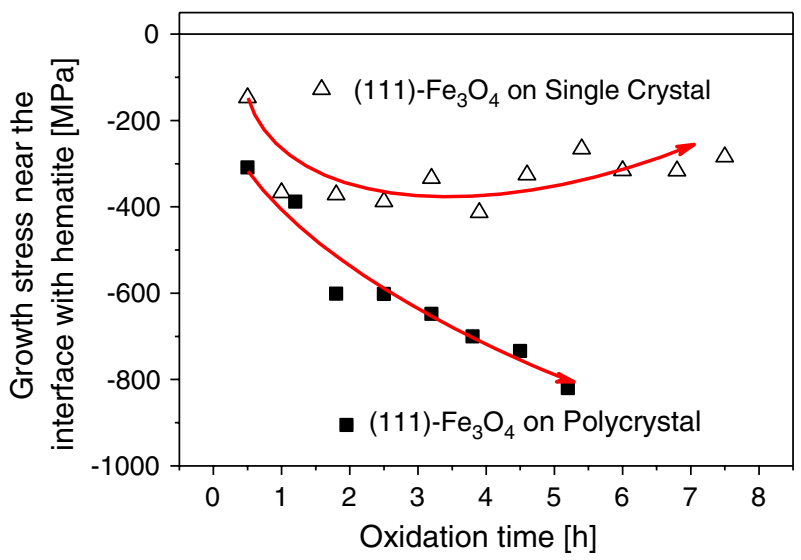

Fig. 15 Evolution of growth stresses in the magnetite layer near the upper magnetite/hematite interface. The stress values stem from the (111) diffraction line of magnetite which has the smallest information depth

gradients, mainly caused by growing compressive stresses near the interface with the hematite top-layer (from -300 to $-600 \mathrm{MPa}$ on Armco iron and from -150 to $-370 \mathrm{MPa}$ on the single crystal substrate). However, with ongoing oxidation the growth stresses near the interface with hematite evolve opposite trends for the different substrates. On Armco iron the growth stresses of magnetite gradually increase to $-800 \mathrm{MPa}$ after $5 \mathrm{~h}$, whereas on the single crystal the growth stresses gradually decrease to $-270 \mathrm{MPa}$ after $7 \mathrm{~h}$ of oxidation. The growth stresses in the middle of the magnetite layer do not significantly change. They are very low (from 50 to $-100 \mathrm{MPa}$ ) for the polycrystalline substrate, and always compressive (from -60 to $-110 \mathrm{MPa}$ ) for the iron single crystal during the entire oxidation.

\section{Discussion}

Evolution of Microstructure in the Iron Oxide Scales

\section{Oxidation Kinetics}

The oxidation kinetics of both iron polycrystals and single crystals can be described by a continually decreasing parabolic behavior. This indicates that the diffusion processes through the iron oxide scale represents the rate-controlling oxidation mechanism. The presence of grain boundaries at the Armco iron surface leads the initial oxidation rate of the polycrystalline substrate to be more than twice faster than that of the single crystal substrate.

As the hematite and magnetite layers thicken, diffusion through the iron oxide scale starts to slow down. This causes a transition region which cannot be described by an individual growth law (parabolic, direct-logarithmic, or inverse-logarithmic) but only through a combination of them. After $3 \mathrm{~h}$ of oxidation the parabolic rate 
constant reaches constant values for both substrates. The oxidation rate of the polycrystal is slightly lower than the one of the single crystal due to the increased porosity observed at the magnetite/Armco iron interface (Fig. 6b). This transient oxidation behavior agrees with earlier observations of Caplan et al. [26, 41], Paidassi [42], Graham [43] and Chen [21].

\section{Microstructure}

The oxide scales grown on iron polycrystals and single crystals with (110) surfaces at $450{ }^{\circ} \mathrm{C}$ develop similar two-phase scales containing hematite and magnetite. The thicknesses of the topmost hematite layers increase only very slowly to about $0.33 \mu \mathrm{m}$ during $10 \mathrm{~h}$ of oxidation, whereas magnetite evolves layer thicknesses of about $8 \mu \mathrm{m}$. Consequently, the ratio of $\mathrm{Fe}_{3} \mathrm{O}_{4}: \mathrm{Fe}_{2} \mathrm{O}_{3}$ changes with the oxidation time. On polycrystalline substrates it increases from 11.6:1 after $1 \mathrm{~h}$ to 22.5:1 after $10 \mathrm{~h}$ of oxidation, whereas it changes from 11.6:1 after $1 \mathrm{~h}$ to $27.5: 1$ after $10 \mathrm{~h}$ of oxidation on single crystal substrates. Similar results have also been presented in [21].

The magnetite layers develop on both substrates a duplex structure with an inner seam of small globular grains at the magnetite/substrate interface and an outer layer of long columnar grains. In contrast to earlier observations [44], these duplex layers were observed on both substrates since $1 \mathrm{~h}$ of oxidation, where no scale detachment occurs (Fig. 4). A few pores could be detected only in the scale grown on the iron polycrystals next to the interface between the columnar and globular sub-layers after $5 \mathrm{~h}$ of oxidation. This indicates that these thin fine-grained layers do not simply grow through traversing channels caused by inner oxide dissociation along grain boundaries. The globular seam seems therefore to be also related to a region of magnetite nucleation during the early oxidation stages as suggested in [45]. The ratio between the columnar and globular magnetite layers vary from 7:1 after $1 \mathrm{~h}$ to 10.5:1 after $10 \mathrm{~h}$ of oxidation for both substrates. This shows that these inner layers represent only $17-12 \%$ of the entire layer thickness, as reported in [21, 46].

Detailed microstructure studies by EBSD revealed after $5 \mathrm{~h}$ of oxidation that the average grain area of the columnar magnetite layer grown on Armco iron is $27 \%$ larger than on the iron single crystal. The larger grain size together with the similar grain aspect ratios found for the magnetite layer on both substrates lead to an average intercept length which is almost twice as large for the polycrystalline substrate as for the single crystal substrate.

At lower temperatures the growth of magnetite is controlled by the diffusion of iron ions along grain boundaries [44, 46, 47]. The larger intercept length observed in the magnetite layer formed on the polycrystalline substrate causes a smaller amount of grain boundaries lying perpendicular to the scale/substrate interface. Less vertical grain boundaries in magnetite and the slightly thicker hematite layer also favor the lower parabolic oxidation constant of Armco iron (Table 2).

\section{Porosity}

The iron oxide scale grows initially free of pores on both substrates. With ongoing oxidation porosity develops in the upper half of the magnetite layer. The pores are 
mostly very small, i.e. sizes $<1 \mu \mathrm{m}$, thus indicating that they can be related to the type of defects in magnetite $[6,48,49]$. On Armco iron void coalescence occurs at the interface with the substrate (Fig. 6b). This produces also coarse pores, increasing their volume fraction in comparison to the single crystal substrate. An exact description of the mechanisms of voiding within these iron oxide scales is, however, beyond the scope of the present study. Through scale porosity could not be observed for both substrates. This reinforces our assumption that oxide dissociation along grain boundaries is not the only mechanism causing the growth of magnetite duplex layers.

Evolution of Crystallographic Texture in the Iron Oxide Scales

\section{Magnetite}

The overall texture of the magnetite layers grown at $450{ }^{\circ} \mathrm{C}$ was weak during the first $10 \mathrm{~h}$ of oxidation independent of the substrate type. These observations agree with the predictions of Blàchere et al. [50], that the ion mobility inside an oxide is low for oxidation temperatures far below $\mathrm{T}_{\mathrm{m}} / 2\left(\mathrm{~T}_{\mathrm{m}}\right.$ is the melting point of the oxide, here $1600{ }^{\circ} \mathrm{C}$ for magnetite), causing a competitive oxide grain growth in the direction of the ion flux, i.e. parallel to the direction of the surface normal. This produced on both substrates predominantly columnar magnetite layers which consist of stacks of magnetite grains without a strong crystallographic preferred orientation.

The preferential orientation of oxide growth, even when it is not very sharp, reflects the energy balance between epitaxial strains and growth velocity. Growth velocity has often a crystallographic dependence. The fastest growth rates occur in the crystal direction having the lowest surface free energy. The balance between epitaxial strains and growth velocity depends on the distance from the substrate surface, temperature and partial pressures at which the crystals grow [51].

The growth of columnar magnetite grains is preceded by the formation of a fine equiaxed seam in contact with the iron substrates. EBSD-studies after $1 \mathrm{~h}$ of oxidation reveal that the entire duplex layer grown on the iron single crystal exhibits a weak $\{110\}$ fiber texture in the direction of the surface normal (Fig. 7). The texture strength is higher for the inner than for the outer layer. The same result is obtained from the texture analyses performed in situ using ED diffraction, which also reveal in magnetite growing on the single crystal substrate a weak $\{110\}$ texture pole in the normal direction after 30 min of oxidation (Fig. 11).

These observations suggest that the magnetite crystallites growing during the first moments of oxidation on the (110) surface of the iron single crystal attempt at following the out-of-plane orientation of the substrate which represents a possibility to minimize the misfit between both crystal lattices. When the scale thickness is sufficiently thin (usually less than $1 \mu \mathrm{m}$ [3]) during the early oxidation and the interface area between the first-formed grains is consequently small, these epitaxial strains prevail over the surface energy, thus determining the driving force for oxide growth.

The $\{110\}$ fiber texture observed in the magnetite layer after $1 \mathrm{~h}$ of oxidation of the iron single crystal indicates once again that the inner globular sub-layer is also a 
result of the first nucleated magnetite grains and not only a product of scale detachment and inner re-oxidation, as suggested in [44].

In contrast to the scale formed on the iron single crystal, the entire magnetite layer on Armco iron exhibits after $1 \mathrm{~h}$ of oxidation an almost negligible $\{001\}$ fiber texture. On a polycrystalline substrate the first-formed oxide grains can not grow with the same out-of-plane orientation of the underlying substrate grain, since the different orientations of the substrate grains would reduce neither the epitaxial strains nor the interface energy. Thus, the oxide grains growing during the early oxidation of a polycrystal attempt at evolving a common crystallographic orientation which will enable an energy reduction. This becomes possible in the $\{001\}$ crystallographic direction of magnetite which appears to have the lowest surface energy, as suggested in [45]. Because of the low ion mobility inside the scale, the resulting $\{001\}$ preferred orientation is not strong during these initial oxidation stages.

With ongoing oxidation the epitaxial strains decay as a result of increasing layer thicknesses. This leads the interface energy between the oxide grains to drive the energy balance for the long-term growth of magnetite on the iron single crystal $[1,3,52]$. Thus, the $\{001\}$ fiber of magnetite grows in both sub-layers on the single crystal substrate at the expense of the $\{110\}$ fiber. This could be observed by ex situ EBSD investigations (Fig. 8) as well as by in situ texture analyses using ED diffraction (Fig. 11).

In case of the polycrystalline substrate, the $\{001\}$ fiber also dominates during the long-term oxidation. However, the texture strength observed after $5 \mathrm{~h}$ of oxidation of the single crystal is reached in the layer growing on the polycrystal only after $10 \mathrm{~h}$ (Fig. 8). The longer oxidation time required for reaching the same degree of preferential orientation appears to be caused by the slower long-term oxidation kinetics of the polycrystal, which is related to the void coalescence at the interface with the substrate (Fig. 6b).

These results confirm the trend reported for other naturally grown oxides [53, 54], that a certain exposure time is required to establish a specific texture in oxide scales.

\section{Hematite}

The oxidation of magnetite to hematite has been investigated many times with contradictory observations. Epitaxial growth of the basal planes of the hematite on the (111) magnetite lattice planes has been observed in [11, 55, 56], but it has also been reported [57, 58] that a non-epitaxial growth of the hematite occurs on magnetite, and that the reaction rates do not depend on the surface orientation. If epitaxy would play a role in the growth of the hematite on magnetite, the basal planes of the hematite would be tilted about $54^{\circ}$ with respect to the magnetite surface according to the crystallographic relationships $\mathrm{Fe}_{3} \mathrm{O}_{4}$ (111) $[110] / / \mathrm{Fe}_{2} \mathrm{O}_{3}$ (001) [100] and $\mathrm{Fe}_{3} \mathrm{O}_{4}$ (111) [101]// $\mathrm{Fe}_{2} \mathrm{O}_{3}$ (001) [100] proposed in [59].

We, however, observed that the basal planes of the hematite grow on both substrates with only a slight preferential orientation. The weak orientation of the hematite platelets does not agree with the epitaxial relationships either, since they appear nearly perpendicular to the interface with magnetite. This suggests that the growth of the hematite on the magnetite within the low-temperature regime could be 
driven by crystallographic orientations of low surface energy, i.e. of faster growth velocities.

Internal Stress Formation in Two-phase Iron Oxide Scales

\section{Magnetite}

Initially, magnetite evolves compressive growth stresses which are similar for both substrates and lower than those observed in the hematite layer (Fig. 13a, b). The internal stress state during the early oxidation stages, where a thin and adherent scale is formed with a low fraction of grain boundaries, can be interpreted in terms of epitaxial strains and/or volumetric changes caused by oxide growth.

Epitaxy can at least partly account for the initial internal stress state at the interface of magnetite with the single crystal substrate. Assuming that the orientation relationship $\mathrm{Fe}(110)[001] / / \mathrm{Fe}_{3} \mathrm{O}_{4}(110)$ [-110] exists between neighboring grains $[60,61]$, the misfit between the iron atoms in the [-110] direction of one magnetite unit cell $\left(\mathrm{d}_{110}-\mathrm{Fe}_{3} \mathrm{O}_{4} \sim 0.5922 \mathrm{~nm}\right)$ and the [001] direction of two iron unit cells $\left(2 * \mathrm{~d}_{100}-\mathrm{Fe} \sim 0.5733 \mathrm{~nm}\right)$ is of approximately $3 \%$. The larger dimensions of the oxide unit cell imply therefore that the magnetite grains will undergo high compressive stresses close to the interface with the iron single crystal. The same conclusion can be derived from the volumetric change caused by oxidation. Since the volume of magnetite is larger than the one of iron, magnetite should evolve compressive stresses at the interface with the iron polycrystal [62].

In contrast to the above expectations, the initial stress distribution in the magnetite layer on the single crystal showed decreasing compression towards the oxide/metal interface, whereas the compressive stresses of the non-epitaxial magnetite layer on Armco iron almost fully relaxed when approaching the substrate (Fig. 14). Since the stress gradients determined on the Armco iron substrate follow the same trend as those forming on the iron single crystal, oxide creep appears to contribute in both substrates to stress relief towards the magnetite/iron interface during the initial oxidation. According to [63] magnetite creeps under the observed growth stresses at $450{ }^{\circ} \mathrm{C}$. This is particularly favored by the growth of fine globular grains at the interface with both substrates (Fig. 5). In the Armco iron substrate the substrate grains contribute additionally to increase creep deformation at the magnetite/iron interface, in comparison with situation on the iron single crystal. This leads either to a complete stress relief or even to slight tension in magnetite at the interface with the polycrystalline substrate (Fig. 14a). These results confirm furthermore that creep strain is always a relevant stress relieving process of thin oxide layers with equiaxed grain morphology, as it has been recently reported for other fine-grained oxide scales [64-66].

Unlike the situation at the magnetite/iron interface, the initial stress state of magnetite close to its upper interface with hematite is influenced by the volumetric strain between the first-formed grains of magnetite and hematite. Epitaxial strains in this case can be excluded based on our texture studies. Although it has been shown that volumetric differences due to oxide growth are not the unique mechanism of 
internal stress formation [1-3], they are still reported to be a relevant cause of growth stresses in oxide scales [67-69].

Oxygen can be considered as the diffusing specie at the magnetite/hematite interface [56]. Thus, the volumetric change in the iron lattice due to inward migration of oxygen ions, as in the model originally proposed by Pilling and Bedworth [4], can be applied to the magnetite/hematite interface. The correspondent Pilling-Bedworth Ratio (PBR) defined as $\mathrm{V}_{\mathrm{Fe}}\left(\mathrm{Fe}_{2} \mathrm{O}_{3}\right) / \mathrm{V}_{\mathrm{Fe}}\left(\mathrm{Fe}_{3} \mathrm{O}_{4}\right)$, where $\mathrm{V}_{\mathrm{Fe}}$ represents the volume of the corresponding oxide per iron atom, amounts to 1.02 [62]. This indicates that magnetite should evolve tensile stresses at the interface with hematite due to its smaller atomic volume. This holds, however, only for layers which do not penetrate each other. Hematite grows as platelets which partially intergrow the magnetite layer (see Fig. 10b and [23]), thus generating high compressive stresses in their vicinities [26] (Fig. 16). This is in accordance with our results showing increasing compressive stresses towards the interface with hematite.

With increasing layer thicknesses the ion flux through grain boundaries becomes more relevant, increasing the compressive growth stresses of magnetite in both substrates, particularly in the outer regions (Fig. 14). It has been shown [46] that iron diffuses faster than oxygen along the grain boundaries of magnetite, thus new oxide is rather formed in the outer region of the magnetite layer. This is corroborated by the increasing compressive stresses observed towards the uppermost regions of magnetite. Our microstructure studies further reveal void formation in outer magnetite regions on both substrates with ongoing oxidation. Porosity is associated with shrinkage which also contributes to stress-depth profiles with decreasing compressive stresses towards the interface with the substrate.

Simultaneously, magnetite crystals grow within voids and grain boundaries, reinforcing internal compression. This mechanism seems to be relevant in the more porous magnetite layer growing on Armco iron, thus causing a steady increase of the compressive stresses near the interface with hematite (Fig. 15). In the magnetite layer formed on the single crystal substrate, on the other hand, stress relief clearly takes place in regions of higher compressive stresses near the upper interface after $4 \mathrm{~h}$ of oxidation (Fig. 15). Creep of the long columnar magnetite grains with their grain boundaries located perpendicular to the in-plane growth stresses seems to be
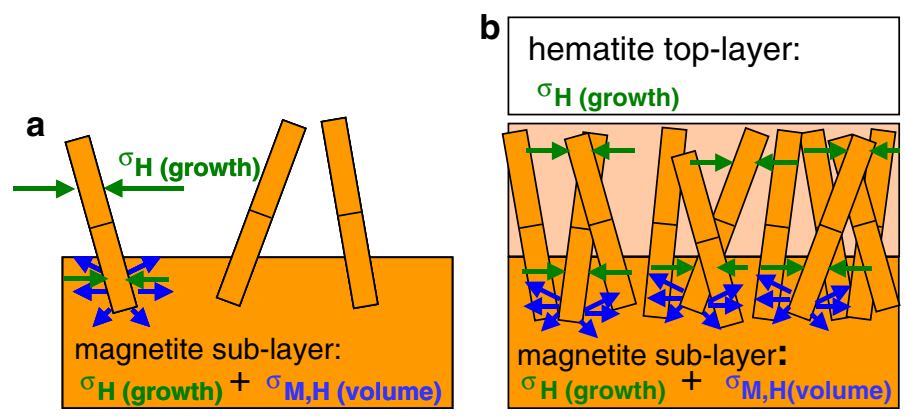

Fig. 16 Schematic growth stress state at the magnetite-hematite interface after short (a) and after long oxidation time (b) 
unlikely. Thus, stress relief in the more intact magnetite layer growing on the iron single crystal can be attributed to creep of the very fine-grained hematite layer associated with the absence of inner oxide growth at porosity.

\section{Hematite}

The effect of epitaxial misfits on the stress state of the hematite during oxidation should be negligible, since the texture strength of the hematite for both substrates is even lower than that of magnetite and the weak preferential orientations observed do not correspond to the epitaxial relationships reported in the literature $[11,55,56,59]$. Nevertheless, hematite has a greater unit cell volume than magnetite [62] and its growth occurs predominantly by diffusion through short-circuit paths [70]. During the early oxidation stages this rapidly leads to compressive stresses in hematite which are significantly higher than in magnetite.

Although creep deformation is slower in hematite than in magnetite, if the same oxide grain size is considered [71], the hematite grains fromed here are by far smaller, i.e. $\ll 1 \mu \mathrm{m}$ size (Fig. 10), than those of the magnetite layer. Thus, with ongoing oxidation the hematite layer shall creep faster than the columnar magnetite grains. Because of the intergrowth of both iron oxides, however, stress relief occurs in the hematite layer growing on the iron single crystal (Fig. 13b) at rates similar to those observed in magnetite. On the other hand, increased porosity and void coalescence at the interface with the Armco iron substrate causes hematite to grow within voids. This seems to counterbalance stress relief by creep, thus leading to nearly invariable compression with increasing oxidation times.

\section{Conclusions}

We studied the evolution of microstructure and internal stresses in oxide scales growing on iron polycrystals and on (110) surfaces of iron single crystals at $450{ }^{\circ} \mathrm{C}$ in order to determine the effect of substrate microstructure on the stress situation in multiphase oxide scales forming within the low-temperature oxidation regime of iron.

In situ EDXRD using synchrotron radiation provided unique information regarding:

- the gradients of growth stresses in magnetite layers during oxidation of iron substrates;

- the time evolution of fiber texture in oxide scales.

The investigations revealed that:

- iron polycrystals oxidize faster than iron single crystals only during the first minutes of oxidation;

- magnetite evolves duplex layers independent of the substrate microstructure;

- the globular inner layer stems from a region of magnetite nucleation; 
- the magnetite grains first-nucleated on iron single crystals grow epitaxially following the surface orientation of the substrate. Later, $\{001\}$ fiber textures evolve preferentially, as in the case of polycrystalline substrates;

- during oxidation compressive growth stresses arise in hematite as well as in magnetite independent of the substrate microstructure;

- the growth stresses of magnetite exist in the form of gradients which are characterized in both substrates by higher compressive stresses near the interface with hematite;

- the low growth stresses observed next to the magnetite/iron interface shows that creep of the fine-grained magnetite layer at the interface with the substrate is a relevant source of stress relief;

- the long-term growth stresses of the magnetite are governed by concurrent processes of pore formation, inner oxide growth and oxide (or oxide and substrate) creep.

Acknowledgments The authors would like to thank BESSY for the allocation of beamtime. Thanks are extended to I. Denks, J. Gibmeier, G. Wagener (HMI Berlin) for experimental support during the diffraction experiments with synchrotron radiation. Dr. A. Kostka and Dr. C. Barbatti (MPIE) are acknowledged for their help during the SEM and EBSD sessions. This work was funded by the "Fonds zur Förderung der wissenschaftlichen Forschung" FWF, Vienna, Austria. Further support was provided by the European Community within the framework of the Research Infrastructure Action under the FP6 Program "Structuring the European Research Area"-Contract RII3-CT-2004-506008.

Open Access This article is distributed under the terms of the Creative Commons Attribution Noncommercial License which permits any noncommercial use, distribution, and reproduction in any medium, provided the original author(s) and source are credited.

\section{References}

1. M. Schütze, in Protective Oxide Scales and their Breakdown, ed. D. R. Holmes, chap. 4 (The Institute of Corrosion and Wiley Series on Corrosion and Protection, John Wiley \& Sons Ltd, Chichester, UK, 1997).

2. D. J. Baxter and K. Natesan, Reviews on High Temperature Materials 5, 149 (1983).

3. H. E. Evans, International Materials Reviews 40, 1 (1995).

4. N. B. Pilling and R. E. Bedworth, Journal of the Institute of Metals 29, 529 (1923).

5. F. N. Rhines and J. S. Wolf, Metallurgical Transactions 1, 1701 (1970).

6. A. Atkinson, Corrosion Science 22, 347 (1982).

7. D. R. Clarke, Acta Materialia 51, 1393 (2003).

8. B. Pieraggi and R. A. Rapp, Acta Metallurgica 36, 1281 (1988).

9. N. Vallino, L. Lahoche, J. M. Roelandt, V. Lorman, S. B. Rochal, L. Gaillet, and G. Moulin, Computational Materials Science 19, 329 (2000).

10. E. A. Gulbransen and K. F. Andrew, Journal of the Electrochemical Society 106, 511 (1959).

11. W. E. Boggs, R. H. Kachik, and G. E. Pellisier, Journal of Electrochemical Society: Eletrochemical Science 114, 32 (1967).

12. A. G. Goursat and W. W. Smeltzer, in Oxidation of iron, High-temperature Materials, Coatings, Surface Interactions, ed. J. B. Newkirk (Freund Publ House, Tel Aviv, 1980).

13. F. Reichel, L. P. H. Jeurgens, and E. J. Mittemeijer, Acta Materialia 56, 2897 (2008).

14. A. H. Heuer, A. Reddy, D. B. Hovis, B. Veal, A. Paulikas, A. Vlad, and M. Rühle, Scripta Materialia 54, 1907 (2006).

15. B. J. Kooi, M. A. J. Somers, R. H. Jutte, and E. J. Mittemeijer, Oxidation of Metals 48, 111 (1997). 
16. B. Panicaud, J. L. Grosseau-Poussard, P. Girault, J. F. Dinhut, and D. Thiaudière, Applied Surface Science 252, 8414 (2006).

17. S. Corkovic and A. R. Pyzalla, Materials and Corrosion 55, 341 (2004).

18. B. Panicaud, J. L. Grosseau-Poussard, P. O. Renault, J. F. Dinhut, D. Thiaudière, and M. Gailhanou, Applied Surface Science 206, 149 (2003).

19. B. Panicaud, J. L. Grosseau-Poussard, and J. F. Dinhut, Applied Surface Science 252, 5700 (2006).

20. R. Krishnamurthy and D. J. Srolovitz, Acta Materialia 52, 3761 (2004).

21. R. Y. Chen and W. Y. D. Yuen, Oxidation of Metals 59, 433 (2003).

22. R. H. Jutte, B. J. Kooi, M. A. J. Somers, and E. J. Mittemeijer, Oxidation of Metals 48, 87 (1997).

23. M. J. Graham and R. J. Hussey, Oxidation of Metals 15, 407 (1981).

24. R. J. Hussey, D. Caplan, and M. J. Graham, Oxidation of Metals 15, 421 (1981).

25. R. J. Hussey and M. Cohen, Corrosion Science 11, 713 (1971).

26. D. Caplan, M. J. Graham, and M. Cohen, Corrosion Science 10, 1 (1970).

27. W. Reimers, A. R. Pyzalla, A. Schreyer, and H. Clemens, in Neutrons and Synchrotron Radiation in Engineering Materials Science, chap. 10 (Wyley-VCH, Weinheim, Germany).

28. Ch. Genzel, I. A. Denks, J. Gibmeier, M. Klaus, and G. Wagener, Nuclear Instruments and Methods in Physics Research, Section A: Accelerators, Spectrometers, Detectors and Associated Equipment 578, 23 (2007).

29. Ch. Genzel, C. Stock, and W. Reimers, Materials Science and Engineering A 372, 28 (2004).

30. H.-R. Wenk, S. Matthies, J. Donovan, and D. Chateigner, Journal of Applied Crystallography 31, 262 (1998).

31. V. Hauk, in Structural and Residual Stress Analysis by Nondestructive Methods, chap. 2.072 (Elsevier, Amsterdam, 1997).

32. Ch. Genzel, Materials Science and Technology 21, 10 (2005).

33. B. Eigenmann, B. Scholtes, and E. Macherauch, Materialwissenschaft und Werkstofftechnik 21, 257 (1990).

34. I. A. Denks and Ch. Genzel, Nuclear Instruments and Methods in Physics Research, Section B: Beam Interactions with Materials and Atoms 262, 87 (2007).

35. A. Reuss, Zeitschrift für Angewandte Mathematik und Mechanik 9, 49 (1929).

36. M. Van Leeuwen, J.-D. Kamminga, and E. J. Mittemeijer, Journal of Applied Physics 86, 1904 (1999).

37. A. Landolt-Börnstein, in Condensed matter-Ferroelectrics and Related Substances III/36, Oxides, eds. Y. Shiozaki, E. Nakamura, and T. Mitsui (Springer Verlag, 2001).

38. R. W. Rice, Journal of Materials Science Letters 13, 1261 (1994).

39. U. Welzel and E. J. Mittemeijer, Journal of Applied Physics 93, 9001 (2003).

40. U. Welzel, J. Ligot, P. Lamparter, A. C. Vermeulen, and E. J. Mittemeijer, Journal of Applied Crystallography 38, 1 (2005).

41. D. Caplan and M. Cohen, Corrosion Science 6, 321 (1966).

42. J. Paidassi, Acta Metallurgica 4, 227 (1956).

43. M. J. Graham, Corrosion Science 12, 683 (1972).

44. A. Atkinson, Reviews of Modern Physics 57, 437 (1985).

45. B.-K. Kim and J. A. Szpunar, Scripta Materialia 44, 2605 (2001).

46. A. Atkinson and R. I. Taylor, High Temperature High Pressures 14, 571 (1982).

47. C. Gleave, J. M. Calvert, D. G. Lees, and P. C. Rowlands, Proceedings of Royal Society London A379, 409 (1982).

48. L. Tan, Y. Yang, and T. R. Allen, Corrosion Science 48, 4234 (2006).

49. L. Tan, Y. Yang, and T. R. Allen, Corrosion Science 48, 3123 (2006).

50. J. R. Blachère, E. Schumann, G. H. Meier, and F. S. Pettit, Scripta Materialia 49, 909 (2003).

51. H. R. Wenk and P. Van Houtte, Reports on Progress in Physics 67, 1367 (2004).

52. P. Kofstad, in High Temperature Corrosion (Elsevier Applied Science Publishers LTD, Essex, UK, 1988).

53. H. Al-Badairy, D. J. Prior, and G. J. Tatlock, Materials at High-temperatures 22, 453 (2005).

54. D. Naumenko, B. Gleeson, E. Wessel, L. Singheiser, and W. J. Quadakkers, Metallurgical and Materials Transactions A 38A, 2974 (2007).

55. L. E. Lagoeiro, Journal of Metamorphic Geology 16, 415 (1998).

56. R. M. Cornell and U. Schwertmann, in The Iron Oxides (VCH, Weinheim, Germany).

57. Y. Zhou, X. Jin, Y. M. Mukovskii, and I. V. Shvets, Journal of Physics: Condensed Matter 16, 1 (2004). 
58. T. Kendelewicz, P. Liu, C. S. Doyle, G. E. Brown Jr, E. J. Nelson, and S. A. Chambers, Surface Science 453, 32 (2000).

59. H. El Abdouni, A. Modaressi, and J. J. Heizmann, Reactivity of Solids 5, 12 (1988).

60. R. F. Mehl and E. L. McCandless, Transactions of the American Institute of Mining and. Metallurgical Engineers 125, 531 (1937).

61. L. E. Collins and O. S. Heavens, in Proceedings of the Physical Society, Sect. B65(10), art. no 114, (1952), p. 825.

62. T. E. Mitchell, D. A. Voss, and E. P. Butler, Journal of Materials Science 17, 1825 (1982).

63. A. G. Crouch and J. Robertson, Acta metallurgica et materialia 38, 2567 (1990).

64. B. W. Veal, A. P. Paulikas, and P. Y. Hou, Nature Materials 5, 349 (2006).

65. P. Y. Hou, A. P. Paulikas, B. W. Veal, and J. L. Smialek, Acta Materialia 55, 5601 (2007).

66. B. W. Veal and A. P. Paulikas, Journal of Applied Physics 104, 093525 (2008).

67. H. L. Bernstein, Metallurgical Transactions A 18 A, 975 (1987).

68. K. Ueno, S.-I. Pyun, and M. Seo, Journal of the Electrochemical Society 147, 4519 (2000).

69. C. Xu and W. Gao, Materials Research Innovations 3, 231 (2000).

70. H. S. Hsu, Oxidation of Metals 26, 315 (1986).

71. H. J. Frost and M. F. Ashby, in Deformation Mechanism Maps: The Plasticity and Creep of Metals and Ceramics, chap. 14 (Elsevier, 1982). 